\title{
The airline long-haul fleet planning problem: The case of TAP service to/from Brazil
}

\author{
Joana S. Carreira \\ PhD Candidate \\ CITTA - Department of Civil Engineering - University of Coimbra \\ Polo II - 3030-788 Coimbra - Portugal
}

Guglielmo Lulli

Senior Lecturer

Lancaster University - Management School

Lancaster LA1 4YX - United Kingdom

António P. Antunes

(Corresponding Author)

Professor

CITTA - Department of Civil Engineering - University of Coimbra Polo II - 3030-788 Coimbra - Portugal

Phone: +351 239797139 - Fax: None - Email: antunes@dec.uc.pt 


\title{
The airline long-haul fleet planning problem: The case of TAP service to/from Brazil
}

\begin{abstract}
In this paper, we study a strategic fleet planning problem faced by TAP, the Portuguese legacy carrier. The study is intended to shed light on the aircraft models to select, as well as on the mix of aircraft to purchase (or financially lease) and the aircraft to operationally lease in order to cope with the forecasted passenger demand between Lisbon and Brazil in the year 2020. The approach we developed for addressing this problem is based on an optimization model that can be cast in the class of two-stage stochastic integer programs. In our opinion, the proposed approach can be a valuable alternative or complement to the methods currently used in practice. The results of the study provide clear insights on how TAP should renovate its fleet, obviously depending on the available resources. The leasing of aircraft is an option that should definitely be taken into consideration by TAP, since it allows the carrier to deal with demand uncertainty without investing large amount of resources in the purchase of new aircraft.
\end{abstract}

Keywords: transportation; fleet planning; air transport; integer optimization; stochastic programming. 


\section{Introduction}

Strategic fleet planning is a crucial process within any transportation company. It relates to decisions on the fleet size and, in the case of a fleet with different types of vehicles, on the fleet composition. In the aviation industry, these decisions are extremely critical, being undoubtedly among the most important ones that administrators of commercial airlines have to make. Buying a (new) wide-body aircraft like the Airbus 330-200 or the Boeing 787-8 requires an investment of more than \$200M (200 million USD), and even rather small aircraft like the Bombardier CRJ700 or the Embraer 170 cost over \$20M.

Investment costs are certainly a major factor in a fleet planning process but are not the only drivers. As part of this process, airlines must decide which aircraft suit their network; when they are needed; how many are required; and whether they are needed for replacement or for enlarging the fleet size. There are several criteria - partly conflicting - that need to be considered in addition to the investment costs, such as, technical, operational and environmental performance, and cabin comfort. Another important influencing factor is fleet commonality, i.e., the number of aircraft of the same type, the same aircraft family, or the same manufacturer in a fleet. The relevance of one criterion with respect to the others is specific of the air carrier. For instance, at Lufthansa operating costs are of more concern than investment costs because they are "for the rest of the asset's life" (Baldwin 2012). As such, the focus is put on fuel burn, and carbon and noise emissions. Moreover, fleet planning decisions reflect the adopted business model. In general, low-cost air carriers operate a fleet consisting of one model or family of aircraft. The choice delivers operational simplicity and economies of scale vital to budget airlines. On the other side, large network air carriers operate several different aircraft types to better meet customer requirements and serve different markets.

The study herein presented deals with fleet planning issues currently being faced by TAP Portugal, the Portuguese legacy carrier. Some 20 years ago, TAP defined the expansion of service to/from Brazil to be its foremost strategic direction. This direction has been pursued rather successfully since then, and in 2014 TAP was by far the leading carrier in the Europe-Brazil market offering 65 weekly flights each way between Portugal and 9 Brazilian cities, 61 based in Lisbon and the other 4 in Oporto, against only 11 flights per week serving 3 cities in the mid-1990s. Twelve aircraft Airbus 330200 are currently used to operate the flights to/from Brazil, seven of which are aged 15 
years or more. The main scope of the Brazil TAP study was to analyze fleet planning decisions, which depend on the aircraft to replace, to cope with the forecasted passenger demand between Portugal and Brazil in the year 2020. Specifically, the study was intended to shed light on the aircraft models to be selected, as well as on the mix of aircraft to be bought (or financially leased) and aircraft to be operationally leased. The latter alternative is certainly costlier but avoids TAP to invest in aircraft that will be unnecessary in case the evolution of demand is below expectations. In the study, we assumed that, in the future, all TAP long-haul operations will be based in one single airport, Lisbon, to avoid the very high costs involved in the Oporto-based flights.

The main component of the methodology we developed for our study is a stochastic mixed-integer optimization model. Fleet planning problems have often been approached with integer programs as attested by the extensive literature quoted in a recent review paper by Hoff et al. (2010). However, none of the works cited there presents models that deal specifically with commercial aviation. Due to the lack of models devoted to the subject or not, and as stated in an authoritative textbook by Belobaba et al. (2015, Ch. 7), in practice airlines primarily rely on spreadsheet-based financial methods when making fleet planning decisions. The authors of the textbook manifest their surprise that the tools airlines employ for supporting such expensive decisions are far from being as sophisticated as the ones they apply to e.g. flight scheduling or revenue management problems. The mathematical model we developed for this study can be, in our opinion, a valuable alternative or complement to the methods currently used in practice, notably because it allows an in-depth screening of the decision space.

This paper is structured as follows. In the next section, we provide a detailed description of TAP service to Brazil and on the fleet planning problem TAP faces with regard to this market. This is followed by the presentation of the methodological approach we adopted to tackle this problem. The two key components of our approach are subsequently dealt with: first, the procedure we used to forecast demand; and then, the optimization model we developed to address long-haul fleet planning problems under uncertain demand (represented by means of scenarios). The results obtained through the application of the model to the reference planning case considered in the Brazil TAP study are described afterwards, together with an analysis of their sensitiveness to changes in a number of key features. The final section of the paper summarizes the contents of the study and indicates directions for the fleet planning work we intend to carry out in the near future. 


\section{Study Background}

In this section, we provide essential background materials about the Brazil TAP study. In particular, detailed information is given about the network of long-haul flights, the demand for TAP flights between Portugal and Brazil, and the aircraft fleet that makes these flights. All the information provided refers to the first part of 2014, the time when the study was initiated.

\subsection{Flight network}

The network of TAP includes long-haul flights to 14 destinations in Africa and the Americas (Table 1). The vast majority of these destinations correspond to either Portuguese-speaking countries (namely, Angola, Brazil and Mozambique) or important immigration countries for Portuguese nationals (the United States and Venezuela). The share of Brazil in this network is substantial, as this country accounts for 9 of the 14 destinations served by TAP (64\%) and for 65 of the 84 long-haul flights (77\%) it operates every week.

The 9 Brazilian destinations served by TAP correspond, in general, to the metropolitan regions with a population of at least 2.5 million (Figure 1 and Table 2). The only exceptions are Curitiba, which is not served by TAP flights despite its 3.1 million inhabitants, and Natal, which is home to only 1.3 million people but is located close to seaside resorts that are considered to be among the best in Brazil and became quite popular in Portugal in the late 1990s.

Table 1. TAP long-haul destinations

\begin{tabular}{ccc}
\hline Continent & Country & City \\
\hline \multirow{2}{*}{ Africa } & Angola & Luanda \\
\cline { 2 - 3 } & Mozambique & Maputo \\
\hline & & Belo Horizonte \\
& Brasília & Fortaleza \\
& Brazil & Natal \\
& & Porto Alegre \\
& & Recife \\
& & Rio de Janeiro \\
& & Salvador \\
& & São Paulo \\
\cline { 2 - 3 } & USA & Miami \\
& Venezuela & New York - Newark \\
\hline
\end{tabular}




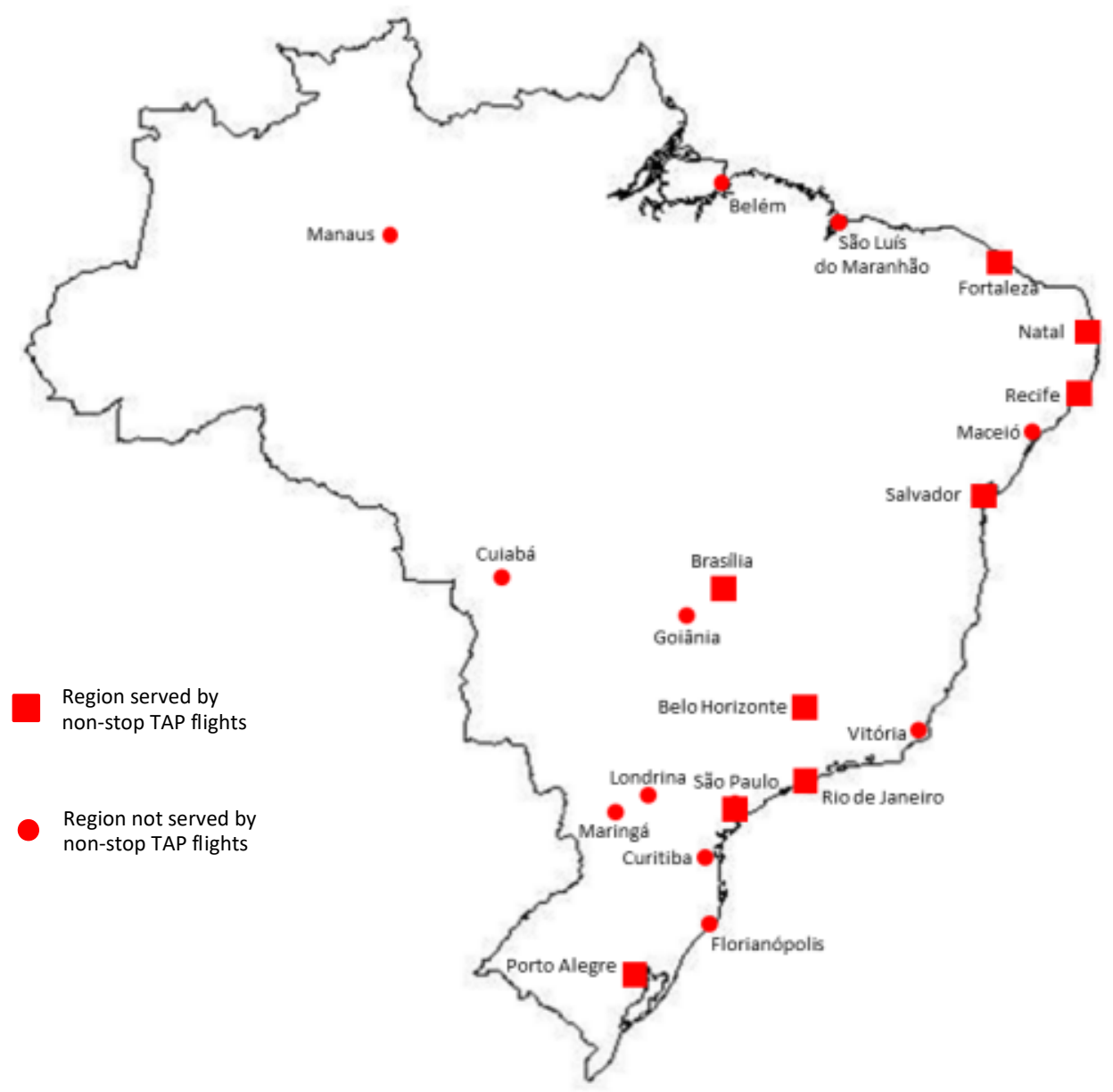

Figure 1. Main metropolitan regions of Brazil

\subsection{Passenger Demand}

The total (leg-based) demand served by TAP through its flights from Portugal to Brazil is in the order of 730,000 passengers per year, approximately $45 \%$ of which initiate or finish their journey in Portugal (naturally, demand for the opposite direction is similar). Almost all other passengers travel to Brazil through Lisbon from European countries, notably Italy and France. This traffic is spread across seasons in a well-balanced manner, being the number of passengers in the most loaded trimester only $28 \%$ above the equivalent figure for the less loaded trimester (Summer and Winter in Europe, respectively). 
Table 2. Population of the main metropolitan regions of Brazil

\begin{tabular}{|c|c|c|c|}
\hline \multirow{2}{*}{ Region } & \multicolumn{2}{|c|}{ Population (million) } & \multirow{2}{*}{$\begin{array}{c}\text { Growth rate } \\
\text { (\%/year) }\end{array}$} \\
\hline & 2000 & 2010 & \\
\hline Belém & 1.839 & 2.102 & 1.35 \\
\hline Belo Horizonte & 4.819 & 5.415 & 1.17 \\
\hline Brasília & 2.051 & 2.570 & 2.28 \\
\hline Cuiabá & 0.726 & 0.834 & 1.39 \\
\hline Curitiba & 2.768 & 3.174 & 1.38 \\
\hline Florianópolis & 0.816 & 1.012 & 2.17 \\
\hline Fortaleza & 3.057 & 3.616 & 1.69 \\
\hline Goiânia & 1.743 & 2.173 & 2.23 \\
\hline Londrina & 0.678 & 0.764 & 1.21 \\
\hline Maceió & 0.989 & 1.156 & 1.57 \\
\hline Manaus & 1.646 & 2.106 & 2.50 \\
\hline Maringá & 0.517 & 0.613 & 1.70 \\
\hline Natal & 1.125 & 1.351 & 1.85 \\
\hline Porto Alegre & 3.719 & 3.959 & 0.63 \\
\hline Recife & 3.338 & 3.691 & 1.01 \\
\hline Rio de Janeiro & 10.869 & 11.836 & 0.86 \\
\hline Salvador & 3.120 & 3.574 & 1.37 \\
\hline São Luís & 1.092 & 1.331 & 2.00 \\
\hline São Paulo & 21.694 & 24.145 & 1.08 \\
\hline Vitória & 1.439 & 1.688 & 1.61 \\
\hline
\end{tabular}

The distribution of passenger demand across the main Brazilian metropolitan regions is shown in Table 3, where we distinguish between the 9 regions that are served by TAP flights and the other 11 most populated regions of Brazil (altogether, these 20 regions generate 707,500 passengers annually each way, thus accounting for $97 \%$ of the total demand). The analysis of the table shows that São Paulo and Rio de Janeiro are by far the most important TAP destinations in Brazil, generating over 125,000 trips, followed by Fortaleza, Salvador and Recife (beach tourism), Belo Horizonte (third-largest metropolitan area) and Brasília (capital city), which generate between 50,000 and 70,000 trips.

The relationship between passenger demand from the 20 metropolitan regions and the population resident in these regions is shown in Figure 2. The visual analysis of this figure clearly indicates that demand and population are strongly positively correlated if metropolitan regions are separated according to whether they are served by TAP flights or not. In the latter case, passengers need to make part of their trips in flights offered by Brazilian airlines, as cabotage is not allowed in Brazil. The examples of Porto Alegre and Curitiba, two metropolitan regions with population between 3 and 4 million relatively close by Brazilian standards (distance by road is approximately $700 \mathrm{~km}$ ), illustrate the impact of non-stop service on traffic in a striking manner: Porto Alegre is 
served by TAP flights and generates about 42,600 yearly trips from Portugal; Curitiba is not and generates less than $1 / 5$ of that number of trips.

Table 3. TAP passenger demand for the main metropolitan regions of Brazil

\begin{tabular}{cccc}
\hline $\begin{array}{c}\text { Region served by } \\
\text { TAP flights }\end{array}$ & $\begin{array}{c}\text { Demand } \\
\left(10^{3} \text { pax/year }\right)\end{array}$ & $\begin{array}{c}\text { Region not served } \\
\text { non-stop by TAP flights }\end{array}$ & $\begin{array}{c}\text { Demand } \\
\left(10^{3} \text { pax } / \text { year }\right)\end{array}$ \\
\hline Belo Horizonte & 61.52 & Belém & 3.31 \\
Brasília & 54.86 & Cuiabá & 1.89 \\
Fortaleza & 62.05 & Curitiba & 7.07 \\
Natal & 38.73 & Florianópolis & 4.36 \\
Porto Alegre & 42.61 & Goiânia & 5.00 \\
Recife & 65.86 & Londrina & 1.60 \\
Rio de Janeiro & 125.04 & Maceió & 1.36 \\
Salvador & 60.18 & Manaus & 4.51 \\
São Paulo & 158.65 & Maringá & 1.36 \\
& & São Luís & 1.71 \\
\hline Total & 669.49 & Vitória & 5.87 \\
\hline
\end{tabular}

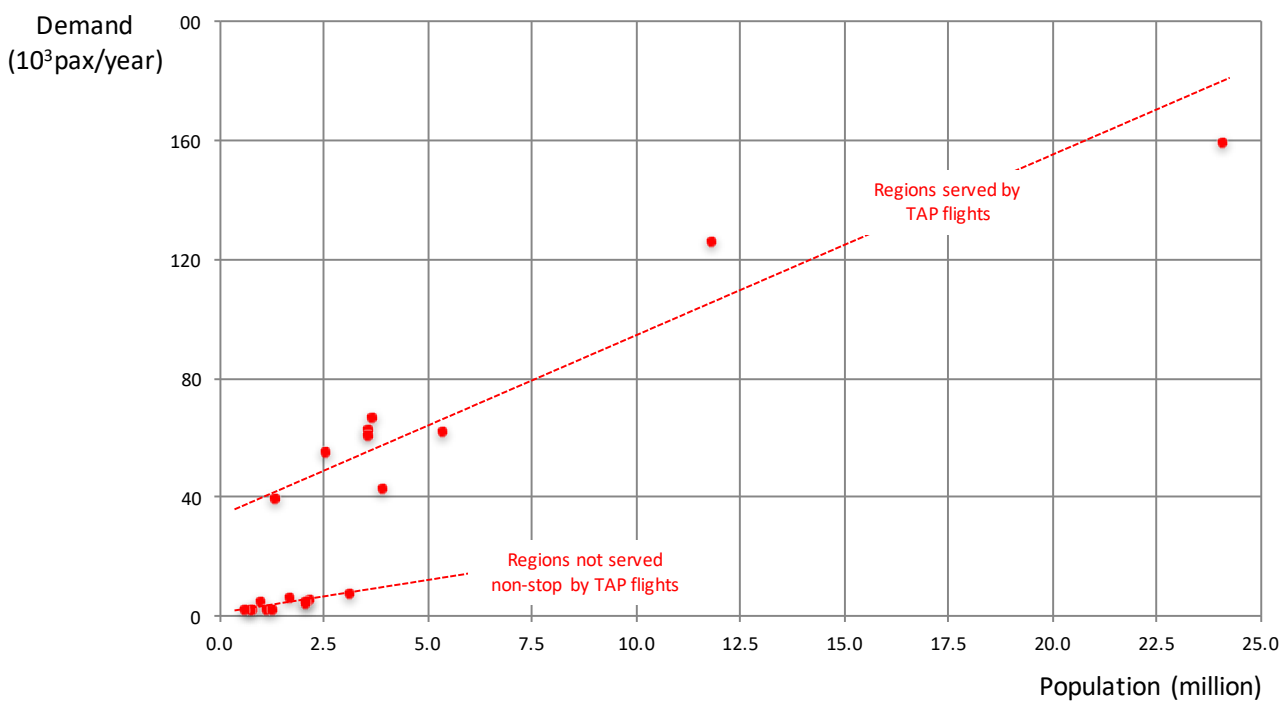

Figure 2. Relationship between TAP passenger demand and population for the main metropolitan regions of Brazil

The connecting airports (or airport systems) for trips with destination to the 11 metropolitan regions that are not served by TAP flights are presented in Table 4 . First of all, this table reveals that, as one could expect, the most important connecting airports correspond to São Paulo, Rio de Janeiro and Brasília, which are in the itineraries of trips to 7, 6 and 5 regions, respectively (the fact that Brasília performs a significant connecting role is due to its capital city status, as well as to its relatively central location in Brazil). It also reveals that only two regions resort to a single connecting airport. These regions are Londrina and Maceió, respectively served through São Paulo and 
Salvador. The airports of Belo Horizonte, Natal, Porto Alegre and Recife are not used by TAP passengers for connections, therefore they are not represented in the table.

Table 4. Connecting airports for metropolitan regions not served non-stop by TAP flights

\begin{tabular}{cccccc}
\hline \multirow{2}{*}{$\begin{array}{c}\text { Metropolitan } \\
\text { region }\end{array}$} & Brasília & Fortaleza & $\begin{array}{c}\text { Rio de } \\
\text { Janeiro }\end{array}$ & Salvador & São Paulo \\
\cline { 2 - 6 } & 17.3 & 67.2 & 15.5 & 0 & 0 \\
Belém & 42.8 & 0 & 10.7 & 0 & 46.5 \\
Cuiabá & 0 & 0 & 37.4 & 0 & 62.6 \\
Curitiba & 0 & 0 & 49 & 0 & 51 \\
Florianópolis & 70.8 & 0 & 0 & 0 & 29.2 \\
Goiânia & 0 & 0 & 0 & 0 & 100 \\
Londrina & 0 & 0 & 0 & 100 & 0 \\
Maceió & 0 & 71.9 & 0 & 28.1 & 0 \\
Manaus & 0 & 0 & 21.5 & 0 & 78.5 \\
Maringá & 24.9 & 75.1 & 0 & 0 & 0 \\
São Luís & 16.5 & 0 & 48.1 & 13.6 & 21.7 \\
Vitória & & & & & \\
\hline
\end{tabular}

\subsection{Aircraft Fleet}

The long-haul fleet of TAP consists of 16 Airbus aircraft, 4 of the A340-300 type and 12 of the A330-200 type. All aircraft are operated in the two-class configuration, with 300 seats in the case of the A340 and 246 seats in the case of the A330. Therefore, the total capacity of the fleet is 4,644 seats, $63 \%$ of which corresponds to the A330. Most of the TAP flights to Brazil are performed with the A330, being the other aircraft essentially used for flying to the other long-haul destinations. This means that $63 \%$ of the long-haul seat capacity of TAP is assigned to $64 \%$ of its destinations and to $77 \%$ of its weekly flights.

The oldest aircraft in the fleet are the 4 A340, all of them with first flights made in 1994 or 1995. Since then, TAP only purchased A330, 7 from the period 1996-2000, thus being now 15 years old or more, and 5 from the period 2006-2010 (Figure 3).

The need to replace the older aircraft employed in Brazil operations was the main driver behind the study herein described. Specifically, the study aims to address the following two questions: first, which types of aircraft should replace the older ones; second, for each aircraft type, how many new aircraft should be bought and how many should be (operationally) leased. 


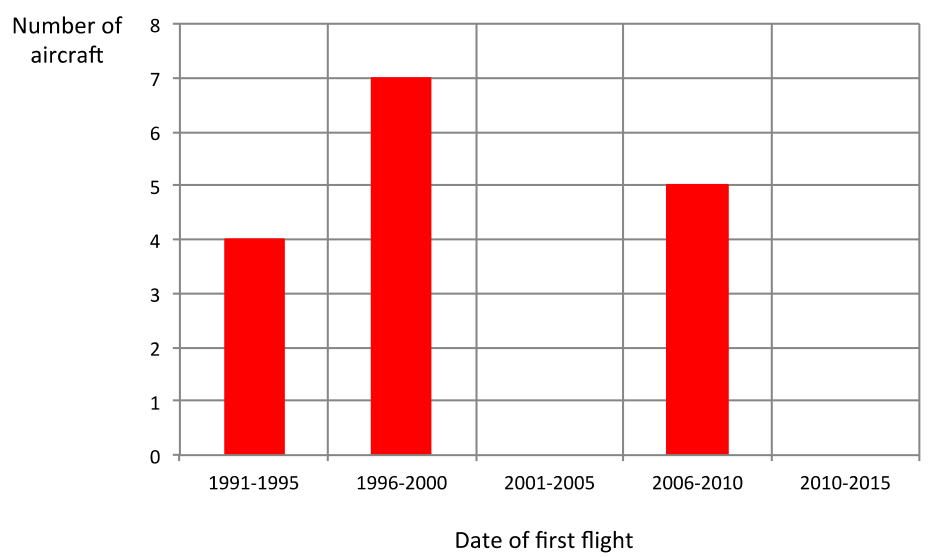

Figure 3. Date of first flight for the aircraft of TAP's long-haul fleet

With respect to the first question, it is worth noting that TAP is, and wants to remain, an all-Airbus airline. This means that the new aircraft must be chosen among the three long-haul aircraft series that Airbus is currently producing: A330; A350; and A380. However, the latter series is not a real option because Lisbon's airport cannot operate A380 aircraft at present, and it is highly unlikely that this situation will change at least in the next 10 years. The possible series from where the new aircraft should be selected are therefore the A330 and the A350.

Regarding the second question, the responses naturally depend on the characteristics of the aircraft, described in Table 5. Observe that the seat capacity refers to the two-class configuration, as TAP offers in the flights to Brazil. It is also worthy to notice that the cruise speed vary only slightly across aircraft types and that flight range for all aircraft types clearly exceed the great circle distance between Lisbon and Porto Alegre, the farthest destination served by TAP in Brazil, which is $8774 \mathrm{~km}$. Therefore, seat capacity and costs are the two features that really matter. As for seat capacity, the use of A350 would allow TAP to offer flights with up to $50 \%$ more seats than the A330 currently used to serve Brazilian destinations. The use of A350 aircraft might therefore be helpful to provide more seat capacity particularly for trips to the main metropolitan regions. As for the costs, based on the information available at TAP, there are two aspects to underline: (a) the A350 have higher capital cost per seat than the A330, but this is compensated by lower operating cost (essentially due to lower fuel consumption); (b) the option of leasing aircraft is approximately $20 \%$ more expensive than the purchasing option, but of course has the advantage of being more flexible, avoiding TAP to make investments that will not be necessary if the demand for Brazilian destinations grows below expectations. 
Table 5. Aircraft Costs and Operational Characteristics

\begin{tabular}{|c|c|c|c|c|c|c|}
\hline \multirow[b]{2}{*}{ Aircraft type } & \multirow[b]{2}{*}{ Seat capacity } & \multirow{2}{*}{$\begin{array}{l}\text { Cruise speed } \\
\qquad(\mathrm{km} / \mathrm{h})\end{array}$} & \multirow[b]{2}{*}{ Flight range $(\mathrm{km})$} & \multicolumn{3}{|c|}{ Costs (\$M) } \\
\hline & & & & Investment & $\begin{array}{c}\text { Leasing } \\
\text { (per year) }\end{array}$ & $\begin{array}{l}\text { Operating } \\
\text { (per year) }\end{array}$ \\
\hline A330-200 & 246 & 871 & 13400 & 216 & 13.0 & 54.0 \\
\hline A350-800 & 276 & 903 & 15300 & 254 & 15.3 & 59.8 \\
\hline A350-900 & 315 & 903 & 14350 & 288 & 17.3 & 67.6 \\
\hline A350-1000 & 369 & 903 & 14800 & 332 & 19.9 & 78.0 \\
\hline
\end{tabular}

\section{Methodological Approach}

The problem faced by an airline when making fleet planning decisions is extraordinarily complex when all its components are taken into account. First of all, the airline needs to look at future demand, which is by nature uncertain, and to its variability across seasons (and months, and days of the week). Generally, this is done considering the long-haul destinations separately from the short- and mid-haul destinations, because they need to be served by fleets with different characteristics (regarding aircraft size and, especially, flight range). Part of the uncertainty airlines have to cope with relates to the demographic and economic evolution of the markets served by the airline, and another part relates to competition from other airlines, including from possible new entrants in those markets. Furthermore, future demand is dependent on the flight frequencies and schedules that the airline will offer in each market, as well as on the many other factors that affect quality of service (seat space and legroom, courtesy of employees, on-time performance, etc.). Finally, airlines need to look at financial issues. Replacing older aircraft is in principle advantageous from the standpoint of operating costs because new aircraft are generally more efficient with regard to fuel consumption. However, purchasing new aircraft requires substantial capital outlays. The alternative is the operational leasing of aircraft, but, in the long term, leasing is more expensive than purchasing.

The methodological approach we adopted in the Brazil TAP study to handle such complex problem, summarized in the diagram of Figure 4, is based on the recognition that it is not realistically possible to achieve practical results without making simplifications. The first task we performed essentially consisted in deciding the simplifications to make and structuring the fleet planning problem faced by TAP regarding its flights to Brazil. This task included discussions with TAP officials to establish the essential components of the problem in hand. 


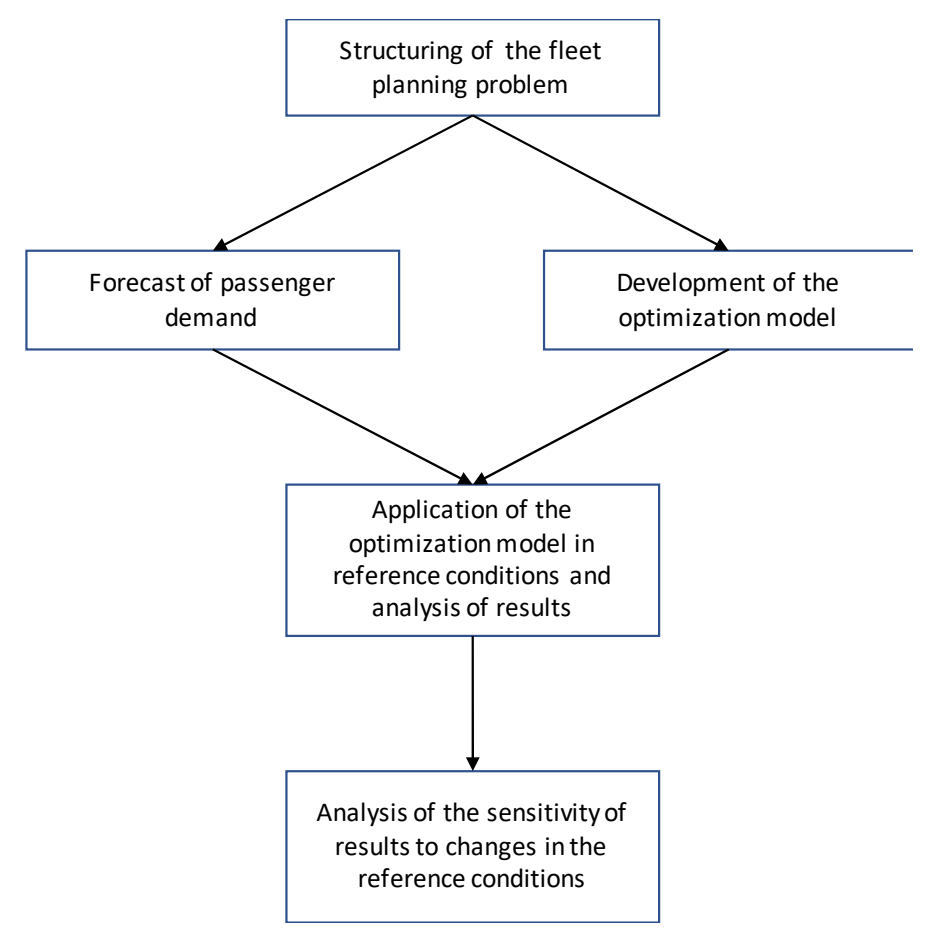

Figure 4. Methodological approach adopted in the study

The first and foremost simplification we made was to separate the demand side of the problem from the supply side. Specifically, we assumed that the fleet should be planned to respond to the passenger demand in 2020. This demand was estimated taken into account the factors explaining the current demand for TAP flights between Portugal and Brazil. Our next task consisted therefore in the realization of a demand forecast. In order to account for uncertainty, several scenarios for future demand were generated.

Practically in parallel with the previous task, we developed the optimization model for determining the least cost fleet that TAP should use in its flights to Brazil, while taking into account all the relevant demand and cost information, as well as the operational constraints involving the possible aircraft to include in the fleet.

The final task we performed consisted in getting the results for our study by solving the optimization model for the demand forecasted in 2020. This task was carried out in two stages: in the first, based on the indications provided by TAP officials, we defined a set of reference conditions and determined the best solution for these conditions using the optimization model developed in the previous task. Second, we conducted a sensitivity analysis to assess the implications on the solution of changes in the reference conditions.

Details about the various tasks are provided in the subsequent sections. 


\section{Demand Forecast}

As stated in the previous section, passenger demand forecast was an important component of our study. It was performed for the reference year of 2020 based on the idea, formed by the observation of Figure 2, that the evolution of this demand for each metropolitan region of Brazil would be properly explained by only two variables: the population resident in the region; and the existence or not of non-stop service to that region (indicator variable). We confirmed this idea through multiple regression analysis. Other possible explanatory variables, such as GDP, international business and tourism, and ticket prices, were considered in the analysis (in addition to the variables mentioned above), but they were never statistically significant. In the case of ticket prices this was not surprising because they are in general very similar no matter the destination.

Among the specifications we used for the relationship between demand and population, the one that provided the best results (probably because, by using logarithms, we circumvented the "size effect" associated with São Paulo and Rio de Janeiro), was as follows:

$\ln Q=a+b \cdot \ln P+c \cdot X+$

where $Q$ is the demand from a metropolitan region; $P$ is the population of the metropolitan region; $X=1$ if the metropolitan region is served non-stop, and $X=0$ otherwise; $a, b$ and $c$ are regression coefficients; and $\varepsilon$ is a normally-distributed error term with zero mean and standard deviation $\sigma$, that is, $\varepsilon \sim N(0, \sigma)$.

The regression results we have obtained for this equation are summarized in Table 6. One can see there that almost $96 \%$ of the variation in data is explained by the equation above $\left(R^{2}{ }_{a d j}=0.958\right)$, and that all regression coefficients are significantly different from zero $(t$ stat $>2)$. The demand modeled by the regression equation fits the observed demand data rather well as also evidenced by the diagram of Figure 5. The apparent exception is for small traffic volumes, whose lower and higher values are overestimated and underestimated, respectively. The regression residuals, i.e. the differences between observed and modeled demand, which can be seen as realizations of the error term, have a zero mean as expected and a standard deviation of 0.327 , and, according to the histogram presented in Figure 6, appear to follow a normal distribution (the number of observations is too small for formal normality testing). 
Table 6 - Summary of regression results

\begin{tabular}{ccccc}
\hline $\begin{array}{c}\text { Adj. } R \text { square } \\
\text { Standard error }\end{array}$ & 0.958 & & & \\
\hline Coefficient & 0.346 & & & \\
\hline$a$ & Value & Standard error & $t$-stat & $p$-value \\
$b$ & 0.865 & 0.111 & 7.814 & 0.000001 \\
$c$ & 0.655 & 0.119 & 5.487 & 0.000040 \\
\hline
\end{tabular}

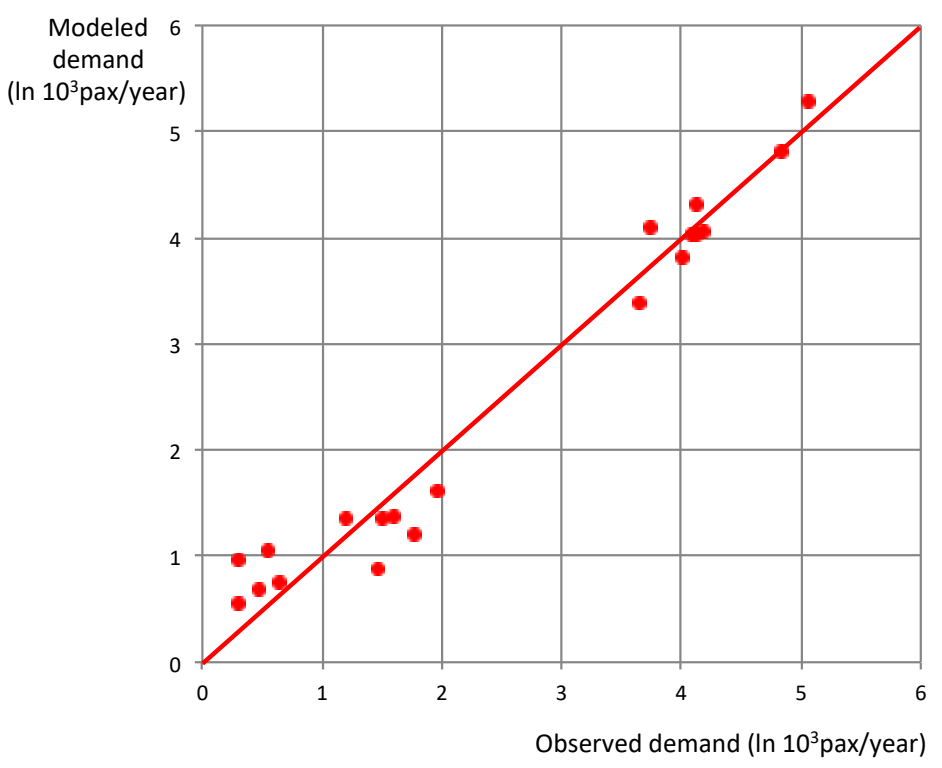

Figure 5. Observed demand vs. modeled demand

Based on the regression results, it is possible to generate equally-probable scenarios for future passenger demand using the following expressions:

- Metropolitan regions served by TAP flights

$$
Q_{f}=e^{(a+c+)} P_{f}^{b}=e^{(3.198+)} P_{f}^{0.655}
$$

- Other metropolitan regions

$$
Q_{f}=e^{(a+)} P_{f}^{b}=e^{(0.865+)} P_{f}^{0.655}
$$

where $Q_{f}$ and $P_{f}$ represent future demand and future population, respectively, and $\varepsilon \sim N(0,0.327)$. 


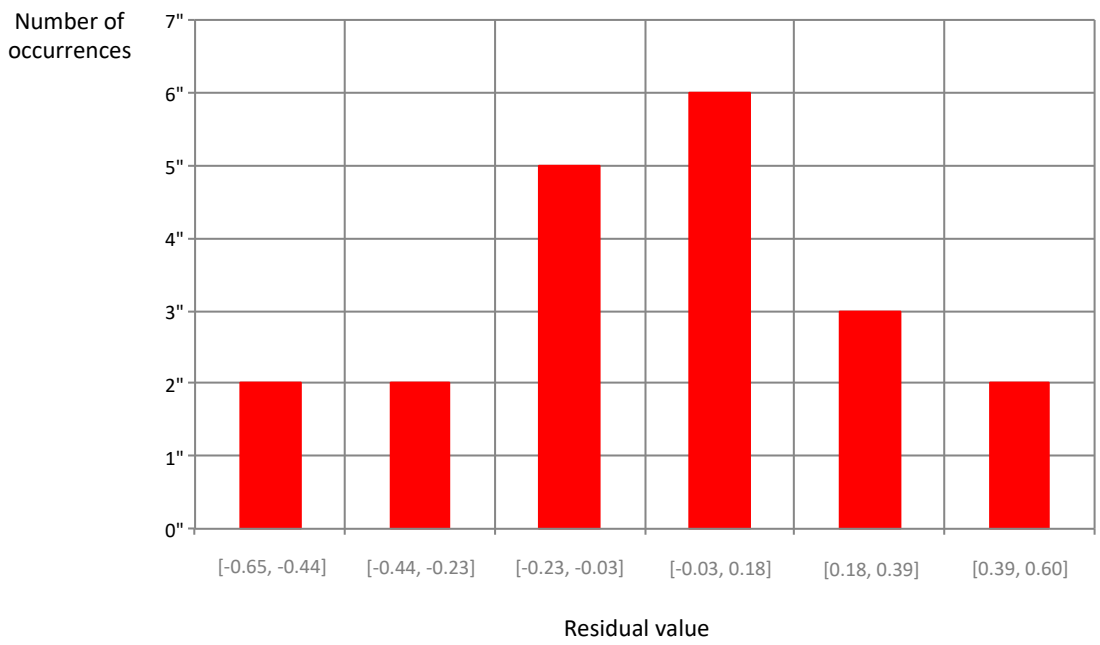

Figure 6. Histogram of regression residuals

\section{Optimization Model}

In this section, after a brief overview of the existing literature on airline fleet planning models, we present the stochastic mixed-integer optimization model we developed for our study. The model was designed with the case of TAP in mind, but could apply to the long-haul fleet of any airline (no matter the number of bases it operates).

\subsection{Literature overview}

Fleet planning problems have been widely studied in maritime and road transport, especially in combination with vehicle routing problems. As described in Hoff et al. (2010), who provided a comprehensive literature review on strategic fleet planning, the mathematical modeling of the problem should include, as detailed as possible, all relevant revenues and costs related to the purchase and operation of the fleet. The models should also take possible long-term contracts and spot markets into account. On the other hand, the inclusion of (detailed) routing aspects is usually meaningless, unless transportation demand is highly predictable.

In air transportation, research in fleet planning problems has been much more limited and has attracted the interest of the scientific community only in recent years. The principal features of the problems are presented in Belobaba et al. (2015, Ch. 7), together with a brief description of the decision support methods used by airlines to address them. In a recent paper, Clegg (2015) described the fleet planning process within British Airways. While economic/financial evaluations and technical/ performance characteristics of alternative aircraft types tend to dominate the fleet 
planning process within most of the airlines, there are several additional aircraft selection criteria that cannot be overlooked.

The economic and financial assessment of the available aircraft alternatives to support fleet planning can be either top-down, i.e., based on high-level aggregate analysis, or bottom-up, based on much more detailed data analysis and forecasts by flight and route. From a financial perspective, Gibson (2010) reviewed many of the current practices in fleet planning, examining the validity and usefulness of financial valuation models from both theoretical and practical perspectives.

Few works that combine both the economic and the business aspects of fleet planning have been carried out. Hsu et al. (2011) developed a stochastic dynamic programming model to optimize airline decisions regarding the purchase, the lease, or the disposal of aircraft over time, and applied it to EVA Airline (Taiwan). The results of their study show that severe demand fluctuations would make the airline lease rather than purchase aircraft, which would allow greater flexibility in fleet management. This can be a reference work for the airlines' replacement decision-making process, as it takes into account both the fluctuations in the demand and the status of aircraft. Along the same lines, Bazargan and Hartman (2012) presented an integer programming model to compute the number of aircraft to buy, lease or sell in order to minimize the total discounted costs over the planning horizon. The authors applied their approach to two United States airlines with different business models. The results show that aircraft leasing was in both cases the best alternative.

From a more operational perspective, Listes and Dekker (2005) studied the fleet planning problem with the goal of determining a robust airline fleet composition with respect to the concept of dynamic allocation of the fleet to routes, in response to shortterm fluctuations in demand. By mean of a stochastic programming model solved with the progressive hedging algorithm, the authors determine the most appropriate fleet given the flight schedule. Thus, the results obtained in this setting should be regarded only as input for the analysis, in which, clearly, many more aspects need to be taken into account before an actual decision is made.

The optimization model we present below combines features from the fleet composition model proposed in Listes and Dekker (2005), which does not consider leasing options, with features from the fleet replacement models proposed in Hsu et al. (2011) and Bazargan and Hartman (2012), which consider the various financing options but disregard important operational issues (e.g. the actual flights that the fleet has to make). 
The main innovation in our model relates to the fact that it combines both types of features, thus capturing the essential components of a long-haul fleet planning problem (without going into details that would compromise its applicability in practice). Moreover, it accounts for seasonal variations of demand and determines endogenously the number of flights for each origin-destination pair (in the Listes and Dekker model flights are made according to a predefined schedule).

\subsection{Model Formulation}

The optimization model we developed for the airline fleet planning problem belongs to the class of two-stage stochastic integer programs (SIPs). We choose the SIP modeling framework because it explicitly represents uncertainty and models a sequence of decision stages that are coherent with the airline decision-making process. Indeed, uncertainty affects many of the problem parameters, especially those referring to passenger demand and to cost structure, i.e., investment (capital), leasing and operating costs. At each stage, the SIP model allows to revise decisions already made based on the new information available. Therefore, it grants more flexibility in the decision-making process and provides solutions hedged against uncertainty, which are not too conservative.

The proposed model formalizes the following sequence of decisions and observations, i.e., realizations of the multivariate random variable representing uncertainty. The first stage decisions relate to the fleet size. More specifically, they concern with the number and the type of aircraft to purchase. Once the realization of the uncertain parameters is observed - e.g., demand for each destination, investment, operating and leasing costs of each aircraft, etc. - the recourse actions are implemented. In our specific model, the recourse actions are decisions about the leasing of aircraft.

We restrict the model to two stages because we are interested in the buying and leasing decisions. Moreover, the two-stage SIPs have been widely studied, are more compact than their multi-stage extensions, and several algorithmic approaches are available in the literature for solving them, see e.g. Schultz (2003) and Sen (2005). Therefore, the practical use of these models is in a rolling horizon fashion, which allows updating the parameters of the instances as soon as new information becomes available.

The optimization model we have developed is based on three key assumptions:

(a) The long-haul flights leave from or arrive to a base (or hub) of the airline that operates them (in the case of TAP we assume that there will be only one base, 
Lisbon). That is, the aircraft serving the long-haul destination, first flies the outbound route from a base airport to the destination, and then flies back to that base airport.

(b) The total duration of a round-trip flight, measured in days, to serve a specific destination can be restricted to one of the following values $\{1.0,1.5,2.0\}$. This assumption, which simplifies the model, represents with good fidelity long-haul operations within airlines in general and TAP in particular. Indeed, airlines typically operate cyclic schedules (i.e. flights take place every day, or regularly, at the same time of the day over a season or a year). The reason is because such schedules help to manage the fleet and the crews, and take advantage of the slot allocation priority rules applied by all the main airports worldwide outside the United States, including Lisbon (IATA, 2012). For instance, for the flights between Lisbon and Brasília, the aircraft leaves from Lisbon at 9:30 am, lands in Brasília at 5:20 pm, and flies back to Lisbon at 6:55 pm where it arrives at 6:05 $\mathrm{pm}$, in order to be ready to leave again to Brasília $2 \mathrm{~h} 25 \mathrm{~m}$ later.

(c) The costs of long-haul flights can be taken as a function of the number and type of aircraft that make them, according to TAP officials. This is because the number of aircraft of each type is closely correlated to the number of flights operated by that type of aircraft. However, the proposed model could easily be transformed to account for costs dependent not only on the number and type of aircraft but also on the origin-destinations pairs they serve (as indicated below, a set of its decision variables refers to the number of weekly flights for each origin-destination pair made by each type of aircraft).

In what follows, it is assumed that the random vector $q$, corresponding to passenger demand, has a finite support; that is, $\Xi=\left\{q^{1}, \ldots, q^{S}\right\}$ with probabilities $p_{1}, \ldots, p_{S}$. This hypothesis allows us to represent uncertainty by means of scenarios. A scenario is a realization of the vector of random variables corresponding to an elementary atom $q \in$ $\Xi$.

The model's formulation requires definition of the following notation:

$\underline{\text { Sets }}$
$\boldsymbol{A}$ : set of aircraft types;
$D$ : set of origin-destination pairs; 
$S$ : set of scenarios;

$\boldsymbol{P}$ : set of periods of the year (seasons or months)

\section{$\underline{\text { Parameters }}$}

$r$ : discount rate (/year);

$c i_{a}$ : discounted investment cost of an aircraft of type $a$ (\$/year);

$\mathrm{Co}_{a}$ : operating cost of an aircraft of type $a(\$ /$ year);

$p_{s}$ : probability of scenario $s$;

$c l_{a}$ : leasing cost of an aircraft of type $a$ (\$/year);

$s_{a}$ : capacity (number of seats) for an aircraft of type $a$ (pax);

$f_{a d}=1$ origin-destination pair $d$ is within the range of aircraft $a ; f_{a d}=0$ otherwise;

$q_{d p s}$ : demand for origin-destination pair $d$ in period $p$ and scenario $s$ (pax/week);

$\alpha$ : level of risk protection, i.e., the probability of the scenarios accommodated in the optimal solution;

$t_{d}$ : total duration of a round-trip flight for origin-destination pair $d$, including the turnaround time (days). By assumption (b) above, this parameter may assume one of the following values $\{1.0,1.5,2.0\}$, depending on the distance to the destination;

$n_{a}$ : number of aircraft of type $a$ in the current fleet of the airline that will not be replaced;

$i_{\max }$ : maximum investment in new aircraft $(\$)$;

$i_{\text {min: }}$ minimum investment in new aircraft $(\$)$.

\section{$\underline{\text { Decision variables }}$}

$X_{a}$ : the number of aircraft of type $a$ to buy;

$Z_{a s}:$ the number of aircraft of type $a$ to lease in scenario $s$;

$Y_{s}=1$, if scenario $s$ is accommodated in the optimal solution; $Y_{s}=0$, otherwise;

$V_{a d p s}$ : the number of weekly flights for origin-destination pair $d$ in period $p$ and scenario $s$, using aircraft of type $a$.

$X_{a}$ and $Y_{s}$ are the first stage decision variables, while $Z_{a s}$ and $V_{a d p s}$ are the recourse actions (second stage decision variables). 
As criteria of performance to set the decision variables, we consider the annual expected total costs of the airline $(C)$. The total costs, to be minimized, account for the discounted investment costs, the leasing costs and the operating costs. Given the notation introduced above, the objective-function of the proposed airline fleet planning model can be formulated as follows:

$$
\operatorname{Min} C=\underset{a A}{ }\left(r \cdot c i_{a}+c o_{a}\right) X_{a}+\underset{a A s}{ } p_{s}\left(c l_{a}+c o_{a}\right) Z_{a s}
$$

The minimization of the objective-function is subject to the following set of constraints:

$$
\begin{aligned}
& s_{a} f_{a d} V_{a d p s} \quad q_{d p s} Y_{s} \quad d \quad \boldsymbol{D}, p \quad \boldsymbol{P}, s \quad \boldsymbol{S} \\
& \text { a } A \\
& p_{s} Y_{s} \\
& \text { s } S \\
& \begin{array}{llllll}
{ }_{d} t_{d} V_{a d p s} & \text { 7. }\left(n_{a}+X_{a}+Z_{a s}\right) & a & \boldsymbol{A}, p & \boldsymbol{P}, s & \boldsymbol{S}
\end{array} \\
& c i_{a} X_{a} \quad i_{\max } \\
& c i_{a} X_{a} \quad i_{\min } \\
& X_{a}, Z_{a s}, V_{a d p s} \quad \boldsymbol{Z}_{0}^{+} \quad a \quad A, d \quad \boldsymbol{D}, p \quad \boldsymbol{P}, s \quad \boldsymbol{S} \\
& Y_{s} \quad\{0,1\} \quad s \quad S
\end{aligned}
$$

Constraints (5) are the demand constraints. For each origin-destination pair, period of the year and scenario, these constraints guarantee that passenger demand is satisfied, meaning that the airline will provide enough seat capacity to accommodate the forecasted demand of passengers (and that this capacity is made available in flights that are within the range of the aircraft that make them). Seat capacity depends on the number of connections and the type of aircraft in the airline fleet used to serve a specific origin-destination. Observe that these constraints are enforced only for a subset of scenarios, i.e., those scenarios whose decision variable $Y_{s}$ is set to one. Indeed, in conjunction with constraint (6), which is a probabilistic constraint, not all scenarios are necessarily accommodated in the optimal solution. The rationale for this modeling approach is that satisfying the demand constraints for all possible scenarios can be deemed uneconomical by the airline management. Indeed, if all the scenarios would be accounted in the solution, the first stage decisions of the SIP recourse model would lead to a seat capacity large enough to cover all possible demand outcomes in the next stage. The probabilistic constraint (6) limits the number of scenarios accommodated in the 
optimal solution thus overcoming the potential drawback described above. If airline managers are willing to avoid the risk of not satisfying the demand even in the most demanding scenarios, then they should choose $\alpha=1$. For $0<\alpha \leq 1$, the larger the value of $\alpha$, the smaller will be the risk that demand will not be served.

Constraints (7) are the time constraints. They impose that the total flight time (measured in days per week) does not exceed the total available flight time (measured in days), for each type of aircraft, period of the year and scenario. These constraints set the size of the fleet in order to accommodate all the long-haul flights.

Constraints (8) and (9) set the maximum and minimum investment the airline is willing to make in the purchase of aircraft. The reason for including a minimum investment constraint in the model is because the accounting value of an airline depends on the aircraft it owns, and not on the leased aircraft used in its operations (which correspond to a service that the airline purchases). This is an issue that airline managers will certainly not neglect when making fleet planning decisions.

Finally, expressions (10) and (11) define the domain for the decision variables included in the model.

The model presented above was developed assuming that the airline has the goal of satisfying all the demand taken as reference for the planning of its fleet. The case where the airline considers not satisfying a fraction of that demand (because the corresponding benefits would not compensate for the additional fleet costs), can be easily accommodated in the model. In fact, this is possible by adding a term in the objectivefunction representing the loss of revenues ensuing from the loss of demand, and changing constraint (5) so that seat capacity will cover the reference demand deducted from the lost demand. The formulation of the new objective function (4') and demand constraints (5') would therefore be:

$$
\begin{aligned}
& \operatorname{Min} C=\underset{a A}{ }\left(r \cdot c i_{a}+c o_{a}\right) X_{a}+{ }_{a \boldsymbol{A} s \boldsymbol{S}} p_{s}\left(c l_{a}+c o_{a}\right) Z_{a s} \underset{d \boldsymbol{D} p \boldsymbol{P} s \boldsymbol{S}}{ } p_{s} n_{p} c u_{d p} U_{d p s} \\
& \begin{array}{lllllll}
\boldsymbol{S}_{a} f_{a d} V_{a d p s} & q_{d p s} Y_{s} & U_{d p s} & d & \boldsymbol{D}, p & \boldsymbol{P}, s & \boldsymbol{S}
\end{array} \\
& \text { a } \mathrm{A}
\end{aligned}
$$

where

$n_{p}$ : number of weeks in period $p$;

$c u_{d p}$ : cost of lost demand for origin-destination pair $d$ in period $p(\$ / \mathrm{pax})$;

$U_{d p s}$ : lost demand for origin-destination pair $d$ in period $p$ and scenario $s$ (pax/week). 


\section{Study Results}

In this section, we present the main results for the TAP strategic fleet planning study. As mentioned before, TAP is currently operating flights to Brazil with 12 Airbus A330200,7 of which are 15 years old or older. The study was developed to assist the fleet renovation process, considering the (uncertain) passenger demand from the 20 main Brazilian metropolitan regions expected in the year 2020. More specifically, the study aimed to respond to the following two key questions: (a) which types of aircraft should replace the older ones; (b) for each aircraft type, how many new aircraft should be bought and how many should be (operationally) leased. The aircraft types considered were the A330-200 and the models in the A350 series (800, 900 and 1000), whose key characteristics are shown in Table 5.

As stated when we described the methodological approach adopted in the study, the results were obtained in two stages. First, we solved the model for reference conditions defined with the help of TAP officials. Second, we performed a sensitivity analysis to analyze how the solution would vary in response to changes in those conditions. For solving the model, we used FICO Xpress, a top-market general-purpose integer optimization software, on a PC equipped with a $2.50 \mathrm{GHz}$ Intel Core i5-3210M CPU.

Specifically, the reference conditions we considered in our study were:

(a) Minimum investment costs: $\$ 648 \mathrm{M}$ (corresponding to the purchase of 3 A330200)

(b) Number of A330-200 to replace: 5 (out of the 7 older aircraft of this type operated by TAP)

(c) Operational leasing costs: $20 \%$ higher than (discounted) investment costs.

(d) Number of demand scenarios: 20 (all equally likely)

(e) Level of risk protection (as measured by the percentage of demand scenarios that are accommodated in the solution): $90 \%$

With respect to passenger demand, we relied on three important assumptions. The first one was that the population of the various metropolitan regions of Brazil would grow in the period 2010-2020 at the same rate it has grown in the period 2000-2010. The second assumption was that trips made to the 11 metropolitan regions not served by TAP flights would follow the same itineraries as today, and in the same proportions, as shown in Table 4 (e.g, $17.3 \%$ of the trips between Lisbon and Belém would be made 
through Brasília, 67.2\% through Fortaleza, and 15.5\% through Rio de Janeiro). Finally, the third assumption was that demand variations across the year could be neglected (that is, our model was applied without considering different periods of the year). This assumption is reasonable because seasonality in the flights between Portugal and Brazil is low and may be handled through revenue management practices.

The total weekly demand for the 20 scenarios considered (Scenarios 1-20), as well as for the next 20 scenarios, is depicted on Figure 7. These data were obtained through expressions (2) and (3) using the random number generator of FICO Xpress (random seed equal to 1). We considered the scenarios to be equally probable, but demand for a large number of scenarios should be relatively close to the average as the error term in those expressions follows a normal distribution. It should be noticed that, by a matter of chance, the demand for the first 20 scenarios (and especially for the first 10) is, on average, below the population mean. This has implications on results that we discuss later in this section.

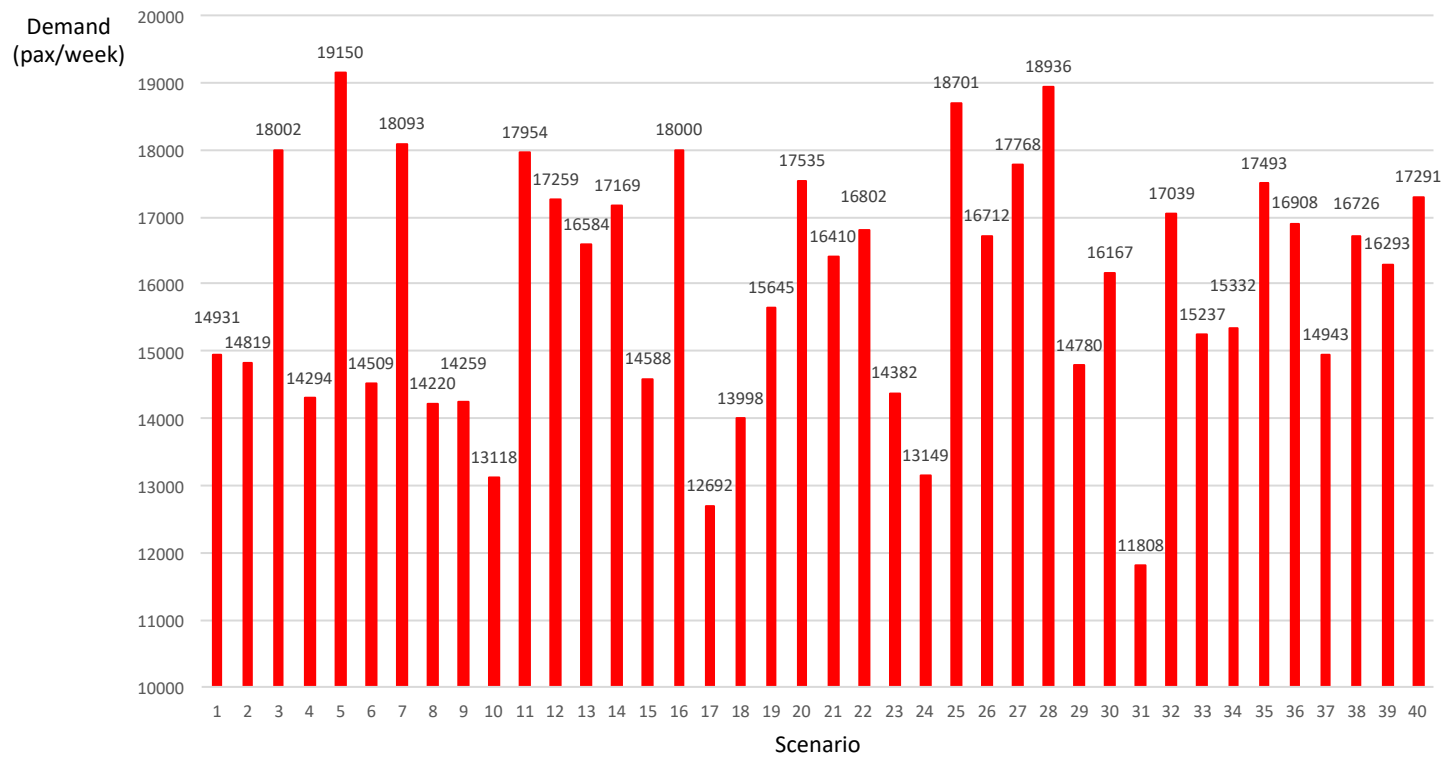

Figure 7. Total weekly demand for $\mathbf{4 0}$ scenarios

To model instances corresponding to the various demand scenarios were solved through the branch-and-cut algorithm implemented in FICO Xpress. Although they were difficult to solve to proven optimality, computational experiments on small-scale instances showed that the algorithm finds the optimal solution in short computational times and then takes a comparatively long time to close the optimality gap. Quite often, solvers show this behavior when tackling integer programs. In view of these experiments, we imposed a time limit of one hour to the computations. For this reason, 
in the remaining of this section, we always speak of best solutions (or best solutions found), and never of optimal solutions.

The results obtained by solving the model in the reference conditions and for the sensitivity analysis are presented and discussed below in separate subsections. Our focus is on fleet composition and size, as well as on costs for the airline and their distribution across categories (investment, leasing, and operating). In addition to this, model runs deliver a wealth of information on solution features, e.g. capacities and flights. We do not provide such information here to avoid extending this paper beyond reasonable limits.

\subsection{Reference Case}

The best solution for the reference case is summarized in Tables 7 and Table 8 . Table 7 displays the number of aircraft to purchase for each type considered (i.e., value of the first stage decisions), the range for the number of aircraft to lease (which is the sum of the second stage decisions and therefore depend on the scenario realization), the investment costs, the expected leasing, operating and (annual-equivalent) total costs. Table 8 reports the value of the second stage decision variables, i.e., the number of leased aircraft for each type. However, for the sake of readability, we only report the values for Scenario 9 (low demand, i.e., 14,259 passengers per week), Scenario 13 (average demand, i.e., 16,584 passengers per week) and Scenario 11 (high demand, i.e., 17,954 passengers per week). These scenarios correspond respectively to the first, second and third quartile of the total demand distribution.

The reference case solution points to the purchase of three aircraft, namely two A330200 and one A350-900, for a total investment of \$720M. This means that only three of the older five aircraft to dismiss are replaced by new purchased aircraft. The required investment exceeds the minimum investment of $\$ 648 \mathrm{M}$ - imposed by constraint (9) of the formulation - by $11.1 \%$. The total expected costs amount to $\$ 745.6 \mathrm{M}$ per year. For the discount rate of $5 \%$ considered in the calculations, the depreciation of the investment costs is $4.8 \%$ of the total expected costs. (Alternatively, observe that, the annual quota of the investment costs amounts to $4.8 \%$ of the total expected costs). The far-reaching component of the total costs is the operating costs $(91.1 \%)$. 
Table 7. Fleet and costs in the reference case solution (Scenarios 1-20)

\begin{tabular}{lcc}
\hline Indicator & \\
\hline Number of new aircraft & $3-8$ \\
Purchased & A330-200 & 2 \\
& A350-800 & 0 \\
& A350-900 & 1 \\
& A350-1000 & 0 \\
Leased & $0-5$ \\
Number of existing aircraft & 7 \\
Total number of aircraft & $10-15$ \\
\hline Investment costs (\$M) & 720.0 \\
Expected leasing costs (\$M/year) & 30.6 \\
Expected operating costs (\$M/year) & 679.0 \\
\hline Expected total costs (\$M/year) & 745.6 \\
\hline
\end{tabular}

Table 8. Purchased and leased aircraft in the reference case solution (Scenarios 1-20)

\begin{tabular}{ccccc}
\hline \multirow{2}{*}{$\begin{array}{c}\text { Type of } \\
\text { aircraft }\end{array}$} & Purchased & \multicolumn{4}{c}{ Number of new aircraft } \\
\cline { 2 - 5 } & & S11 & S13 & S9 \\
\cline { 2 - 5 } A330-200 & 2 & 1 & 2 & 0 \\
A350-800 & 0 & 3 & 1 & 0 \\
A350-900 & 1 & 0 & 0 & 1 \\
A350-1000 & 0 & 0 & 0 & 0 \\
\hline Total & 3 & 4 & 3 & 1 \\
\hline
\end{tabular}

As mentioned above, leasing decisions depend on the realization of the demand scenario. If Scenario 9 occurs, only one aircraft is leased (A350-900), while in the case of Scenario 11 four aircraft - one A330-200 and three A350-800 - are leased. The number and the types of leased aircraft clearly depend on the realization of the air traffic demand. Even though the leasing of aircraft is more expensive, it grants the airline of the flexibility to adjust its own fleet according to the demand realization in all the considered destinations.

Since, by a matter of chance, the demand for the first 20 scenarios we generated is, on average, clearly lower than population mean, we repeated the calculations for Scenarios 21-40. As shown in Table 9, the expected total costs are higher (by almost 3.0\%), but only the leasing and the operating costs increase (14.1\% and 2.6\%). Indeed, the key decisions, the ones concerning the number and the types of aircraft to purchase, are exactly the same (that is, two A330-200 and one A350-900), and therefore the investment costs are also the same. 
Table 9. Fleet and costs in the reference case solution (Scenarios 21-40)

\begin{tabular}{|c|c|c|}
\hline \multicolumn{3}{|l|}{ Indicator } \\
\hline \multicolumn{2}{|c|}{ Number of new aircraft } & 3-8 \\
\hline \multirow[t]{4}{*}{ Purchased } & A330-200 & 2 \\
\hline & A350-800 & 0 \\
\hline & A350-900 & 1 \\
\hline & A350-1000 & 0 \\
\hline \multicolumn{2}{|l|}{ Leased } & $0-5$ \\
\hline \multicolumn{2}{|c|}{ Number of existing aircraft } & 7 \\
\hline \multicolumn{2}{|c|}{ Total number of aircraft } & $10-15$ \\
\hline \multicolumn{2}{|c|}{ Investment costs $(\$ \mathrm{M})$} & 720.0 \\
\hline \multicolumn{2}{|c|}{ Expected leasing costs (\$M/year) } & 34.9 \\
\hline \multicolumn{2}{|c|}{ Expected operating costs (\$M/year) } & 696.9 \\
\hline \multicolumn{2}{|c|}{ Expected total costs (\$M/year) } & 767.8 \\
\hline
\end{tabular}

\subsection{Sensitivity Analysis}

In what follows, we execute an analysis of the sensitivity of the best solution found to (one-at-a-time) changes in the conditions that characterize the reference case.

\section{Minimum investment costs}

We here analyze the effect of the minimum investment costs parameter $\left(i_{\min }\right)$ on the best solution. For this parameter there are two aspects of interest. One concerns with the number of aircraft to purchase when $i_{\min }=0$, i.e., constraint (8) is relaxed; the second is to analyze the effect of this parameter on the mix of aircraft to purchase.

With respect to the first aspect, and as evidenced in Table 10, the number of aircraft to purchase to minimize the expected total costs (in the absence of a minimum investment constraint), is zero. Indeed, as depicted in Figure 8, the expected total costs tend to decrease as investment decreases (and leasing increases). This result, although it may be somewhat surprising, is consistent with the opinions expressed for instance in Wojahn (2012) and by experts of the field with whom we talked about our results (e.g. De Neufville, 2015). It finds explanation in the level of flexibility that airline managers will have for adjusting the fleet mix to the realization of the passenger demand. Indeed, if the airline does not purchase any new aircraft the mentioned level of flexibility will be the maximum possible. However, as highlighted by TAP officials, aircraft ownership increases the financial value of the airline, and this is a factor that cannot be neglected in fleet planning decisions. 
Table 10. Impact of changes in the minimum investment costs

\begin{tabular}{|c|c|c|c|c|c|c|c|}
\hline \multirow{2}{*}{ Indicator } & & \multicolumn{6}{|c|}{ Minimum investment costs (\$M) } \\
\hline & & 0 & 216 & 432 & 648 & 864 & 1080 \\
\hline \multicolumn{2}{|c|}{ Number of new aircraft } & $3-7$ & $3-6$ & $3-7$ & $3-8$ & $4-8$ & $5-7$ \\
\hline \multirow[t]{4}{*}{ Purchased } & A330-200 & 0 & 0 & 0 & 2 & 2 & 4 \\
\hline & A350-800 & 0 & 1 & 2 & 0 & 2 & 1 \\
\hline & A350-900 & 0 & 0 & 0 & 1 & 0 & 0 \\
\hline & A350-1000 & 0 & 0 & 0 & 0 & 0 & 0 \\
\hline \multicolumn{2}{|l|}{ Leased } & $3-7$ & $2-5$ & $1-5$ & $0-5$ & $0-4$ & $0-2$ \\
\hline \multicolumn{2}{|c|}{ Number of existing aircraft } & 7 & 7 & 7 & 7 & 7 & 7 \\
\hline \multicolumn{2}{|c|}{ Total number of aircraft } & $10-14$ & $10-13$ & $10-14$ & $10-15$ & $11-15$ & $12-14$ \\
\hline \multicolumn{2}{|c|}{ Investment costs (\$M) } & 0.0 & 254.0 & 508.0 & 720.0 & 940.0 & 1118.0 \\
\hline \multicolumn{2}{|c|}{ Expected leasing costs (\$M/year) } & 71.4 & 58.5 & 42.8 & 30.6 & 20.3 & 11.9 \\
\hline \multicolumn{2}{|c|}{ Expected operating costs (\$M/year) } & 660.5 & 668.4 & 670.5 & 679.0 & 688.3 & 702.0 \\
\hline \multicolumn{2}{|c|}{ Expected total costs (\$M/year) } & 731.9 & 739.6 & 738.7 & 745.6 & 755.7 & 769.8 \\
\hline
\end{tabular}

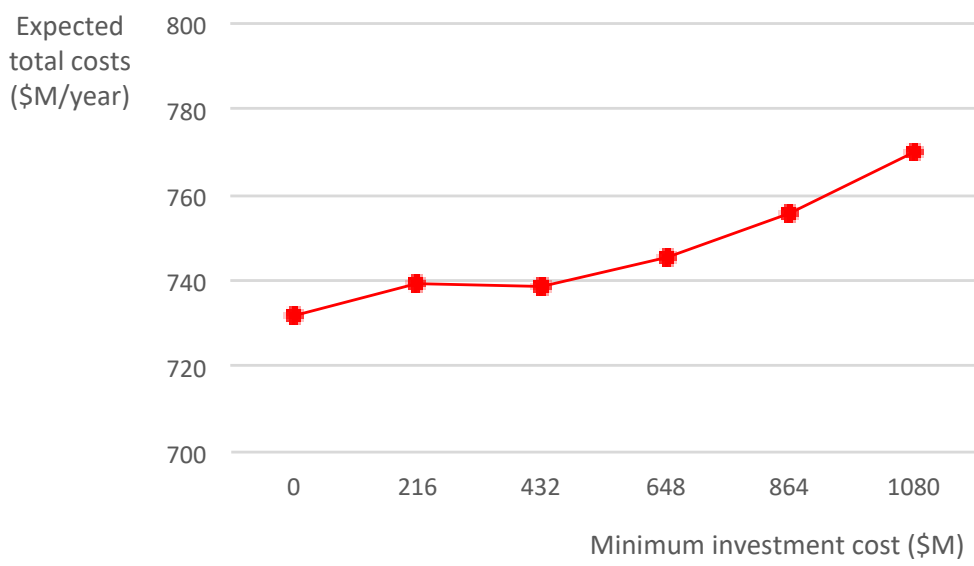

Figure 8. Impact of minimum investment costs on expected total costs

As for the mix of aircraft to purchase, when the parameter $i_{\min }$ is strictly smaller than \$648M (which is the investment required by three A330-200), the best option is the purchase of aircraft of the A350 series, i.e., aircraft with larger seat capacity and larger investment costs, but smaller operating costs per seat. On the other hand, when the minimum investment increases, the solution points to the purchase of smaller size aircraft. Again, these results are consistent and they can be explained by the flexibility of adjusting the fleet mix to the realization of the future demand. In fact, in the former case $\left(i_{\min }<\$ 648 \mathrm{M}\right)$, at most two aircraft can be purchase and the fleet size is of at most nine aircraft. Under all the scenarios, it is necessary to lease at least one aircraft in order to meet the demand. Therefore, the airline has a certain degree of flexibility given by the reduced size of the fleet and can take advantage of the opportunity of diversifying its fleet. It is also interesting to observe that increasing the amount of investments, i.e., increasing the size of fleet, there are scenarios for which the leasing of aircraft is not needed. This situation may signal the case of unused seat capacity; situation that would 
be even more likely and exacerbated if larger aircraft were purchased. Summarizing, the purchase of four aircraft or more is not economically convenient.

\section{Number of A330-200 to replace}

In the reference case, five of the older A330-200 in TAP's fleet are dismissed. In Table 11 we also report the solutions for the cases that consider a number of dismissed aircraft equal to four and six.

Table 11. Impact of changes in the number of $\mathbf{A 3 3 0 - 2 0 0}$ to replace

\begin{tabular}{|c|c|c|c|c|}
\hline \multirow{2}{*}{\multicolumn{2}{|c|}{ Indicator }} & \multicolumn{3}{|c|}{ Number of $A 330-200$ to replace } \\
\hline & & 4 & 5 & 6 \\
\hline \multicolumn{2}{|c|}{ Number of new aircraft } & $3-7$ & $3-8$ & $4-9$ \\
\hline \multirow[t]{4}{*}{ Purchased } & A330-200 & 0 & 2 & 1 \\
\hline & A350-800 & 3 & 0 & 2 \\
\hline & A350-900 & 0 & 1 & 0 \\
\hline & A350-1000 & 0 & 0 & 0 \\
\hline \multicolumn{2}{|l|}{ Leased } & $0-4$ & $0-5$ & $1-6$ \\
\hline \multicolumn{2}{|c|}{ Number of existing aircraft } & 8 & 7 & 6 \\
\hline \multicolumn{2}{|c|}{ Total number of aircraft } & 11-15 & 10-15 & $10-15$ \\
\hline \multicolumn{2}{|c|}{ Investment costs (\$M) } & 762.0 & 720.0 & 724.0 \\
\hline \multicolumn{2}{|c|}{ Expected leasing costs (\$M/year) } & 18.2 & 30.6 & 43.9 \\
\hline \multicolumn{2}{|c|}{ Expected operating costs (\$M/year) } & 685.4 & 679.0 & 676.2 \\
\hline \multicolumn{2}{|c|}{ Expected total costs (\$M/year) } & 741.8 & 745.6 & 756.4 \\
\hline
\end{tabular}

In all the cases, the number of aircraft to purchase is three, which is somewhat imposed by the minimum investment constraint. Increasing the number of dismissed aircraft, the fleet size shrinks and consequently increases the number of leased aircraft. Therefore, exists a direct relationship between the number of leased aircraft and the number of A330-200 dismissed. Obviously, increasing the number of leased aircraft, so do the leasing costs. However, the larger number of leased aircraft has a positive effect on the operating costs as a result of a better adjustment of the fleet mix to the realization of the demand and the inclusion in the fleet of more efficient aircraft. The decrease in operating costs is nevertheless not enough to compensate for the additional leasing costs, and the expected total costs increase with the number of aircraft dismissed.

It is also interesting to note the effect of the number of aircraft to replace on the investment costs. Given the limited "budget" of the airline, reducing the number of dismissed aircraft with the consequent contraction of the leasing costs the airline has the capability to invest more on the purchasing of new aircraft and diversify the fleet, as TAP has already a fleet of $8(=12-4)$ A330-200. Again, fleet diversification is a key point for an effective demand response. On this subject, we should also recall that the 
demand is multidimensional, as we have one demand value for each destination in each scenario.

\section{Operational leasing costs}

For the analysis of the impact of variations in leasing costs, we took them to be $10 \%$ or $30 \%$ higher than (discounted) investment costs, in addition to the $20 \%$ considered in the reference case. The main conclusion was that the increase of leasing costs has a modest impact on the expected total costs, which is not surprising since they account for only a small fraction of the total costs (Table 12). However, because of the interrelations between investment, leasing and operational costs, the variations of one of the listed costs lead to a different cost structure with the consequent change in the fleet mix used to meet demand. When leasing costs are $10 \%$ higher than the discounted investment costs, i.e., in the case of most inexpensive leasing costs, TAP has the opportunity to invest a larger budget on the purchasing of new aircraft. Even if the increment of the investment costs is rather small with respect to the total budget invested, it allows purchasing two A350-800 and one A330-200. Observe that, the total seat capacity of this combination of aircraft is of 798 seats and is smaller than the one obtained with the mix proposed by the solutions of the other two cases (e.g., 20\% and 30\%). In this situation, the airline has more flexibility to adjust the fleet to the different demand scenarios and may operate with better seats occupancy rate. Indeed, this mix is also particularly suitable for scenarios with high demand, as the purchased A350-800 aircraft will be used to serve destinations like Fortaleza and Recife, and larger aircraft will be leased to serve destinations with the higher demand, i.e., São Paulo and Rio de Janeiro. When the leasing of aircraft is more expensive, e.g., 20\% higher than the discounted investment costs or even more, to compensate the higher leasing costs the airline reduces the investment in new aircraft, purchasing two A330-200 and one A350-900. The obtained fleet mix, though flexible to accommodate most of the demand scenario, may require a larger number of leased aircraft in the scenario with highest demand, which is somewhat counterintuitive - higher leasing costs and larger number of leased aircraft. However, this is due to the combination of demand at the different destinations, the fleet owned by the airline and the related interdependencies between the different components of the cost structure. 
Table 12. Impact of changes in operational leasing costs

\begin{tabular}{lcccc}
\hline \multirow{2}{*}{ Indicator } & \multicolumn{3}{c}{$\begin{array}{c}\text { Operational leasing costs } \\
\text { (\% above discounted investment costs) }\end{array}$} \\
\cline { 2 - 5 } & A330-200 & $3-7$ & 20 & 30 \\
\hline Number of new aircraft & 1 & 2 & $3-8$ \\
Purchased & 2 & 0 & 2 \\
& A350-800 & 0 & 1 & 0 \\
A350-900 & 0 & 0 & 1 \\
\multicolumn{1}{c}{ Leased } & A350-1000 & $0-4$ & $0-5$ & $0-5$ \\
Number of existing aircraft & 7 & 7 & 7 \\
Total number of aircraft & $10-14$ & $10-15$ & $10-15$ \\
\hline Investment costs (\$M) & 724.0 & 720.0 & 720.0 \\
Expected leasing costs (\$M/year) & 28.9 & 30.6 & 33.5 \\
Expected operating costs (\$M/year) & 678.5 & 679.0 & 679.3 \\
\hline Expected total costs (\$M/year) & 743.6 & 745.6 & 748.8 \\
\hline
\end{tabular}

\section{Number of demand scenarios}

Our reference case was built upon 20 demand scenarios. This number may look small, but we augmented it and verified that for 30 or 40 scenarios (and even for 60) the best solution found is exactly the same, both with respect to the number and the types of aircraft to purchase and to the range of aircraft to lease (Table 13). In contrast, if only 10 scenarios were considered, the solution would involve a smaller fleet, and one of the aircraft to purchase could be of a smaller size (a A350-800 instead of a A350-900). This indicates that 20 scenarios are enough to deal properly with uncertainty.

Another feature of these results that deserves to be mentioned is the increase of expected total costs with the number of demand scenarios. Normally, the expected total costs should oscillate around the mean while converging to it. This does not occur in this case because, as stated earlier, the average demand for the first 20 scenarios is rather low. Hence, instead of oscillating around the mean, expected total costs converge to the population mean from below, and progressively less quickly as the number of demand scenarios increases. 
Table 13. Impact of changes in the number of demand scenarios

\begin{tabular}{|c|c|c|c|c|c|}
\hline \multirow{2}{*}{\multicolumn{2}{|c|}{ Indicator }} & \multicolumn{4}{|c|}{ Number of demand scenarios } \\
\hline & & \multirow{2}{*}{$\frac{10}{4-7}$} & \multirow{2}{*}{$\frac{20}{3-8}$} & \multirow{2}{*}{$\frac{30}{3-8}$} & \multirow{2}{*}{$\frac{40}{3-8}$} \\
\hline Number of new a & aft & & & & \\
\hline \multirow[t]{4}{*}{ Purchased } & A330-200 & 2 & 2 & 2 & 2 \\
\hline & A350-800 & 1 & 0 & 0 & 0 \\
\hline & A350-900 & 0 & 1 & 1 & 1 \\
\hline & A350-1000 & 0 & 0 & 0 & 0 \\
\hline \multicolumn{2}{|l|}{ Leased } & $1-4$ & $0-5$ & $0-5$ & $0-5$ \\
\hline \multicolumn{2}{|c|}{ Number of existing aircraft } & 7 & 7 & 7 & 7 \\
\hline \multicolumn{2}{|c|}{ Total number of aircraft } & $11-14$ & $10-15$ & $10-15$ & $10-15$ \\
\hline \multicolumn{2}{|c|}{ Investment costs (\$M) } & 686.0 & 720.0 & 720.0 & 720.0 \\
\hline \multicolumn{2}{|c|}{ Expected leasing costs (\$M/year) } & 26.9 & 30.6 & 33.6 & 34.9 \\
\hline \multicolumn{2}{|c|}{ Expected operating costs (\$M/year) } & 653.5 & 679.0 & 692.4 & 697.0 \\
\hline \multicolumn{2}{|c|}{ Expected total costs (\$M/year) } & 714.7 & 745.6 & 762.0 & 767.9 \\
\hline
\end{tabular}

\section{Level of risk protection}

By increasing the parameter level of risk protection $(\alpha)$, we impose that the optimal solution will also accommodate scenarios with the largest air traffic demand (Table 14). Obviously, the higher the level of protection, the higher will be the expected total costs. For instance, in the case of $\alpha=1$, the first stage decisions are also hedged against scenarios with the highest demand. This requires higher investment costs and, in case of realization of the highest demand scenario, higher leasing costs. Moreover, for scenarios with large demand the operating costs will be larger as the airline will operate a larger number of flights in order to meet the demand.

On the other hand, considering a value of $\alpha=0.8$ means that the highest demand scenarios are disregarded and the fleet planning is accomplished by holding a more prudent position with respect to the possibility of increasing the Brazilian air traffic market. Consideration that is also signalled by the reduced amount of investments and the smaller seat capacity, gained with the new purchased aircraft, with respect to the other two cases. 
Table 14. Impact of changes in the level of risk protection

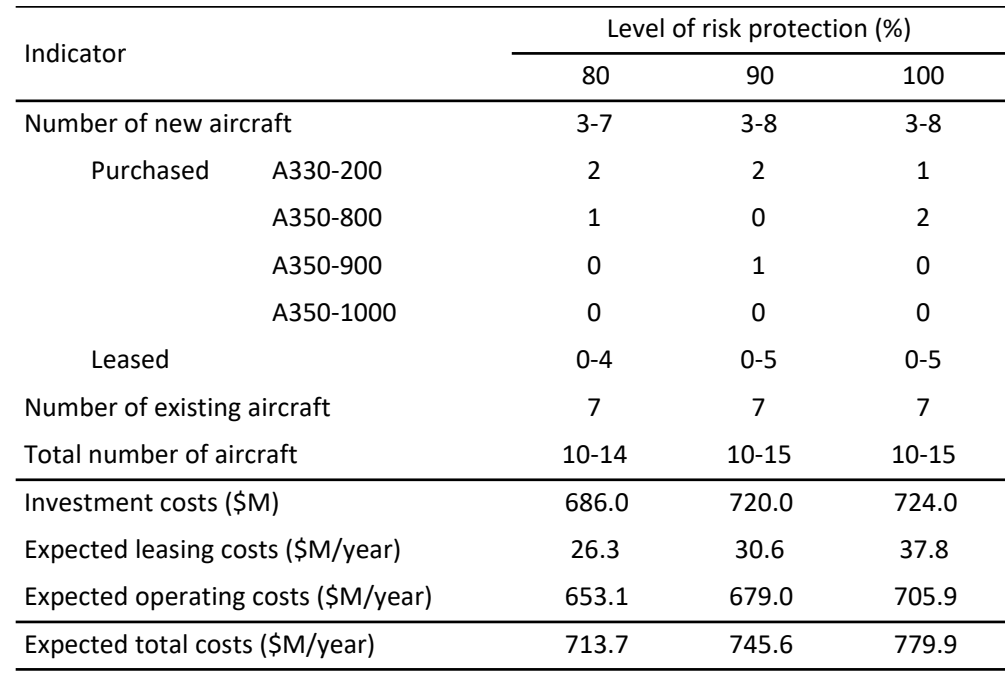

\section{Conclusion}

In this paper, we presented a study on the renovation of the long-haul fleet used by TAP to serve the (uncertain) passenger demand between Portugal (Lisbon) and Brazil in the year 2020. At present, the fleet serving this very important TAP market is rather old, as 7 of the 12 Airbus A330-200 that usually perform the flights are more than 15 years old. The objective of the study was to shed light on the number and the types of aircraft that should replace the older aircraft, and on whether they should be purchased or operationally leased.

To solve TAP's fleet planning problem, we developed a stochastic mixed-integer optimization model that we believe is a relevant addition to the airline planning toolbox currently available. Indeed, despite being relatively simple, the model we developed captures the essential constituents of the problem under analysis, and the results provide very clear insights into how TAP should renovate its fleet. In particular, it has shown that the leasing of aircraft is an option that should definitely be taken into consideration by TAP, since it allows the carrier to deal with demand uncertainty without spending the large amount of resources associated to the purchase of new aircraft.

As recognized by the TAP officials who accompanied the study and discussed its results, the model proposed can be useful in its present form. However, there are some improvements that could increase its value for airlines. One of the possible improvements that we intend to address in the near future relates to decisions on the destinations to serve non-stop by an airline. In the application to TAP, these markets were defined exogenously (they were the same TAP currently serves), but it would not 
be difficult to extend the model so that these markets were defined endogenously. After this extension, the model would become an integrated network design and fleet planning optimization tool. As far as we know, this type of tool does not exist today, and could be of great utility in airline planning processes.

Because the proposed model can be used by airlines with much larger networks than TAP, some effort has also to be devoted to the implementation of more efficient solution algorithms. On this subject, we would like to take advantage of the most advanced features of optimization software (Klotz and Newman, 2013) and of specialized algorithms for stochastic integer programs, see e.g. Schultz (2003) and Sen (2005). For instance, because the proposed model is a stochastic integer program with complete fixed recourse, it can be solved by the Scenario Updating Algorithm (Lulli and Sen, 2006). The Scenario Updating Algorithm has the additional feature that can also be used as a tool for post-optimality analysis, i.e., to explore the influence of outof-sample scenarios on the solution of the stochastic program, similarly to the Contamination Method first proposed by Dupacová (1995) for stochastic linear programs.

\section{Acknowledgments}

The work carried out by Joana S. Carreira for the study described in this paper was funded by the Portuguese Science and Technology Foundation (FCT) through a PhD scholarship (SFRH/BD/51937/2012).

\section{References}

Baldwin, M.A., 2012. Airline fleets: It's all in the planning. AFM Magazine, 21 August 2012. Available at http://www.afm.aero/magazine/airports-and-routes/item/295-airlinefleets-it's-all-in-the-planning, last access May 2015.

Bazargan, M., and Hartman, J., 2012. Aircraft replacement strategy: Model and analysis. Journal of Air Transport Management 25, pp. 26-29.

Belobaba, P., Odoni, A., and Barnhart, C., 2015. The Global Airline Industry, $2^{\text {nd }}$ Ed., John Wiley \& Sons.

Clegg, B., 2015. Reviewing the fleet. Impact, Spring issue, pp. 37-41. 
De Neufville, R., 2015. Discussions during a workshop held in the framework of MIT Portugal's Doctoral Program in Transport Systems (Coimbra, September 24, 2015).

Dupacová, J., 1995. Postoptimality for multistage stochastic linear programs. Annals of Operations Research, 56, pp. 65-78.

Gibson, W.E., 2010. Aircraft Investment Planning and Uncertainty. PhD Thesis, Cranfield University.

Hoff, A., Andersson, H., Christiansen, M., Hasle, G., and Løkketangen, A., 2010. Industrial aspects and literature survey: Fleet composition and routing. Computers \& Operations Research 37 (12), pp. 2041-2061.

Hsu, C.-I., Li, H.-C., Li, S.-M., and Chao, C.-C., 2011. Aircraft replacement scheduling: A dynamic programming approach. Transportation Research Part E: Logistics and Transportation Review 47 (1), pp. 41-60.

IATA, 2012. World Slot Guidelines, $2^{\text {nd }}$ Ed., International Air Transport Association.

Klotz, E., and Newman, A.M., 2013. Practical guidelines for solving difficult mixed integer linear programs, Surveys in Operations Research and Management Science 18 (1-2), pp. 18-32.

Listes, O., and Dekker, R., 2005. A scenario aggregation-based approach for determining a robust airline fleet composition for dynamic capacity allocation. Transportation Science 39 (3), pp. 367-382.

Lulli, G., and Sen, S., 2006. A heuristic algorithm for stochastic integer programs with complete recourse. European Journal of Operational Research, 171 (3), pp. 879-890.

Schultz, R., 2003. Stochastic programming with integer variables. Mathematical Programming 97 (1), pp. 285-309.

Sen, S., 2005. Algorithms for stochastic mixed-integer programming models. In K. Aardal, G.L. Nemhauser, and R. Weismantel (Eds). Discrete Optimization (Handbooks in Operations Research and Management Science 12), Elsevier, pp. 515-558.

Wojahn, O.W., 2012. Why does the airline industry over-invest? Journal of Air Transport Management 19, pp. 1-8. 